\title{
OS CURSOS PRÉ-VESTIBULARES COMUNITÁRIOS E SEUS CONDICIONANTES PEDAGÓGICOS
}

\author{
JOSÉ CARMELO BRAZ DE CARVALHO \\ Departamento de Educação da Pontifícia Universidade Católica do Rio de Janeiro \\ jcarmelo@edu.puc-rio.br
}

\begin{abstract}
RESUMO
Os cursos pré-vestibulares comunitários - CPVCS - enfrentam o dilema de ser simultaneamente movimentos sociopoliticos de empoderamento, diversidade cultural e cidadania ativa, e instituições paraescolares lutando por ações inclusivas no ensino superior. Os estudos sobre os projetos dos CPVCs tendem a ressaltar suas dimensões étnicas, culturais e politicas, enquanto no plano pedagógico sinaliza-se sua filiação às idéias de Paulo Freire e ao pensamento crítico-social. Com base em dados estatísticos extraídos de dois surveys - um com pré-vestibulandos comunitários e outro com seus docentes -, este artigo pretende esboçar os perfis desses atores, mostrar quais são suas percepções sobre currículo, processos de ensino-aprendizagem, avaliação e formação docente. $O$ artigo analisa igualmente a experiência institucional de parceria entre a Pontificia Universidade Católica do Rio de Janeiro PUC-Rio - e os CPVCS na concessão de bolsas de estudo e de bolsas-permanência e na implementação de diversas atividades pedagógicas que não se configuram como uma política pedagógica articulada de inclusão de qualidade. Alternativas são propostas para que a inclusão ocorra não apenas de forma quantitativa, mas que também garanta um ensino de qualidade tanto para o acesso à universidade como para a indispensável consolidação da educação básica.

CURSO PRÉ-VESTIBULAR - EDUCAÇÃO COMUNITÁRIA - ACESSO AO ENSINO SUPERIOR - MÉTODOS DE ENSINO
\end{abstract}

\section{ABSTRACT}

COMMUNITY COURSES FOR COLLEGE ENTRANCE EXAMINATION AND THEIR PEDAGOGICAL CONSTRAINTS. Community courses for college entrance examination CPVCs - face the dilemma of being simultaneously sociopolitical movements of empowerment, cultural diversity, and active citizenship as well as institution belonging to the paraschool system, fighting, thus, for inclusive actions in higher education. Studies on CPVC projects tend to enhance their ethnic, cultural, and political dimensions, pointing out that, from a pedagogical point of 
view, they are linked to Paulo Freire's ideas and the critical social thought. Based on statistical data from two surveys - one conducted with students from community courses for college entrance examination and the other carried out with their teachers -, the main goal of this paper is to draw the profiles of these two actors, identifying their perceptions of curriculum, teaching-learning processes, assessment, and teacher training. The work also analyzes the institutional experience of partnership between the Pontifical Catholic University of Rio de Janeiro - PUC-Rio - and the CPVCS as regards the granting of scholarships and permanence scholarships, and the implementation of various pedagogical activities which do not seem to form a comprehensive pedagogical policy for good quality inclusive education. It offers alternatives for inclusion to occur not only at the quantitative level, but also ensuring good quality teaching for both college access and the fundamental consolidation of basic education.

JUNIOR COLLEGES - COMMUNITY EDUCATION - HIGHER EDUCATION EDUCATIONAL METHODS

Há doze anos, os primeiros alunos dos cursos pré-vestibulares comunitários - CPVCs - ingressavam em cursos de graduação no Grande Rio, no âmbito de uma política institucional da PUC-Rio de assegurar cotas de bolsas integrais a esses estudantes, complementadas por bolsas-continuidade (auxílio-transporte, refeição, material escolar) e por algumas iniciativas acadêmicas tópicas (reforço escolar, apoio psicopedagógico etc.). Entretanto, ainda hoje se ressente de uma reflexão pedagógica mais articulada, seja sobre a formação básica e propedêutica desejável nos CPVCs, seja sobre as iniciativas acadêmicas complementares voltadas à efetiva ação afirmativa de inclusão universitária desses pré-vestibulandos.

Atualmente, com a significativa ampliação de cerca de 220 mil vagas na rede de ensino superior privado no biênio 2005-2006, por meio do Programa Universidade para Todos - Prouni - agora também em cursos de graduação antes bastante seletivos por razões econômicas e acadêmicas -, é relevante consolidar-se um eixo de reflexões pedagógicas sobre a formação prévia proporcionada pelos CPVCs e sobre as alternativas pedagógicas a serem implementadas pelas Instituições de Ensino Superior - IES - associadas ao Prouni, com vistas à efetiva inclusão acadêmica desses alunos.

Este artigo apresenta uma leitura pedagógica sobre os CPVCs, em uma dupla dimensão: a propedêutica ou pré-vestibular e a de educação básica dirigida a adultos. Considera igualmente a experiência institucional de uma universidade ao desenvolver diversas iniciativas pedagógicas mais voltadas ao crescente universo de graduandos comunitários oriundos dos CPVCs. 


\section{ALGUNS PRESSUPOSTOS}

O diagnóstico preliminar aqui esboçado se desenvolve em torno de dois eixos de investigação e de práticas institucionais. $\bigcirc$ primeiro eixo, de considerações mais empíricas, está articulado em duas pesquisas de campo, cujo tema é a forma como docentes e alunos dos CPVCs percebem os fatores pedagógicos em seus cursinhos comunitários. Segundo os critérios técnico-metodológicos de pesquisas sociais definidos por Fred Kerlinger ( 1984, p.386-39|), o processo cumulativo dessas duas investigações consubstancia-se como exploratory field study junto a docentes e alunos de 97 CPVCs no Grande Rio, pelo esforço de mapear um campo temático ainda não consolidado por pesquisas anteriores. Busca-se, assim, identificar dimensões analíticas, construtos e variáveis em relação às questões pedagógicas, por exemplo, como os CPVCs concebem e desenvolvem, teórica e praticamente, suas propostas de ensinoaprendizagem, currículo, avaliação e formação docente.

segundo eixo de considerações sobre o universo pedagógico nos CPVCs tem sido construído desde 1994, quando se iniciaram as experiências institucionais na PUC-Rio, seja pelo do acompanhamento da política de cotas implementada gradualmente pela Vice-Reitoria Comunitária em parceria com uma centena de CPVCs, seja pela coordenação da Graduação de Pedagogia e do Núcleo de Educação de Adultos em articulação com as demais licenciaturas e em negociações interinstitucionais com dirigentes dos CPVCs. Esta segunda linha de sistematização perde o suposto distanciamento possibilitado pelo uso de questionários e entrevistas e ganha a dinâmica das argumentações discursivas construídas pelos diversos sujeitos coletivos e interlocutores institucionais: dirigentes representativos das múltiplas correntes político-pedagógicas que fazem parte do universo dos CPVCs; grupos acadêmicos representativos de concepções mais escolarizadas e/ou de visões educativas próprias de movimentos de educação popular; outros parceiros mais vinculados ao pragmatismo das associações de moradores; organizações não governamentais - ONGs - mais preocupadas com eficácia e eficiência gerenciais; agências governamentais de diversos matizes político-ideológicos.

Nesse amálgama de paradigmas e ênfases contraditórias sobre as funções e os objetivos dos CPVCs, é possível delinear um processo de consensos provisórios na linha incrementalista da racionalidade política (A. Hirschman), ou de 
avanços relativos, segundo teorias da ação comunicativa (Habermas). Evidentemente, há um recorte epistemológico próprio do autor do presente artigo.

Um terceiro pressuposto, explicitado no título do texto - condicionantes pedagógicos -, requer outra digressão. Ao referir-se aos CPVCs, o autor reporta-se a movimentos sociais de comunidades e grupos de excluídos e pobres, lutando por cidadania ativa, defesa da diversidade, empoderamento político e cultural, atuando em geral sob condições objetivas bastante precárias de uma paraescolarização compensatória e de ações inclusivas, com recursos humanos, físicos, financeiros e técnicos bastante limitados. Em contraponto a essas determinações socioeconômicas macroestruturais, há a pressuposição de que os fatores técnico-pedagógicos encontram espaços para se tornar dialeticamente condicionantes, não apenas condicionados.

Operando com pressupostos da teoria do campo de Pierre Bourdieu, como fez Jailson Souza e Silva (2003) em Por que uns e não outros?, entendese que os diferentes determinismos e condicionantes, emergindo das diversas esferas - economia, política, sociedade, contexto comunitário e configurações familiares, instituições sociais parceiras e os habitus dos próprios agentes nos CPVCs (seus coordenadores, docentes e alunos) - constituem-se em forças de influência, no contexto das quais os sujeitos sociais podem ser menos ou mais determinados ("agidos", como o diz Raymond Boudon, 1987, cap. 7), ou agentes de mediações. De que maneira os sujeitos e atores pedagógicos (coordenadores, docentes e alunos) operam sob tantos determinismos? De que maneira suas competências político-educacionais e técnico-pedagógicas desenvolvem mediações como fatores condicionantes? Os quase 12 anos de práticas socioeducacionais dos CPVCs parceiros da PUC-Rio e os surveys examinados neste artigo buscam delinear esses condicionantes pedagógicos, tão bem ressaltados em 1983 pela tréplica entre Dermeval Saviani, Guiomar Namo de Mello e Paolo Nosella (Saviani, 1983).

\section{O UNIVERSO DE 97 CPVCS DO GRANDE RIO}

Dada a pressuposição de mediações pedagógicas exercidas pelos sujeitos coletivos nos CPVCs, é necessário retratar esse universo de "agidos" e agentes sociais sob enfoques dos paradigmas deterministas e interacionistas estudados por Boudon (1987). 
A relevância sociopolítica da formação de docentes-pesquisadores especificamente no contexto da apartação socioeconômica dos CPVCs e de seus precários recursos físicos e humanos - é ressaltada pelos retratos estatísticos gerados a partir dos dois surveys desenvolvidos inicialmente no biênio 2004-2005, com base nas percepções docentes e discentes dos 97 CPVCs parceiros no Grande Rio, bem como em um terceiro momento, pela avaliação diagnóstica formulada pela equipe da Fundação Cesgranrio. Esta foi feita mediante prova simulada sobre 42 questões do Exame Nacional do Ensino Médio - Enem - de anos anteriores (Fundação Cesgranrio, 2005).

$O$ retrato delineado por um primeiro survey junto aos quadros docentes dos CPVCs mostra as condições pedagógicas desafiadoras enfrentadas por eles e por projetos similares de resgate da cidadania educacional desenvolvidos pela sociedade civil, que operam em condições bastante adversas. Basta considerar que $51 \%$ dos docentes e coordenadores dos CPVCs ainda não haviam concluído a graduação à época, 17,2\% eram vestibulandos e 3,2\%, estudantes secundaristas. Esses dados ressaltam a carência de quadros comunitários que, por enquanto, não podem contar com um maior retorno das "gerações escolares ascendentes". Na distribuição dos docentes por áreas científicas, destacamse três aspectos: a presença majoritária de diplomados em Ciências Humanas (60,4\%); o grupo de representantes das Ciências Exatas e Tecnológicas (24,5\%) é duas vezes maior que o dos formados em Ciências Sociais (12,3\%), eventualmente em associação com a crescente presença de cursos pré-técnicos comunitários; a reduzida presença da área Biomédica, talvez decorrente da alta seletividade socioeconômica dos cursos nessa especialização.

O segundo momento do processo de pesquisa anterior foi constituído por um survey desenvolvido junto a 2.783 pré-vestibulandos comunitários, que também enfatiza desafiadoras condições pedagógicas enfrentadas pelos CPVCs parceiros, tais como:

- enquanto apenas $25 \%$ deles se encontram na faixa etária própria do pré-vestibular, 39\% tinham idade superior à prevista para a conclusão do ensino universitário;

- em termos de capital cultural familiar, 51\% dos pais tinham apenas escolaridade fundamental e 38\% das mães haviam concluído somente o antigo ensino primário; 
- quase 50\% declararam uma renda familiar inferior a dois salários mínimos;

- a defasagem entre a conclusão do ensino médio e o curso pré-vestibular era de cerca de dez anos para 20\% dos pré-vestibulandos, enquanto $29 \%$ deles estavam afastados dos estudos por um período de três a cinco anos;

- em referência a uma nota auto-atribuída à qualidade do seu ensino médio (em escala de zero a dez), 28\% conferiram nota inferior a cinco a seus cursos; enquanto $34 \%$ deu nota sete (moda) à qualidade de seus estudos secundários;

- cerca de 48\% consideravam os conteúdos programáticos dos CPVCs dissociados das suas experiências de vida.

Após essa leitura empírica do universo dos CPVCs parceiros da PUCRio, é relevante complementar esse retrato quantitativo com uma tentativa de tipologia qualitativa, de natureza ideológico-educativa, acerca de seus principais projetos político-pedagógicos. Como qualquer outra tipologia, em especial em uma área ainda incipiente de estudos, correm-se riscos de demasiada simplificação e de enquadramentos indesejáveis. Portanto, com os devidos caveats acadêmicos, procura-se esboçar uma tipologia político-pedagógica como um recurso didático em apoio a leitores menos familiarizados com os CPVCs.

Neste tópico, são delineados cinco possíveis cenários de institucionalização dos CPVCs, a partir da identificação de seus eixos mais marcantes nas formas de organização social e/ou política, de sua militância e engajamento político-cultural e religioso, de focalizações sobre alternativas de promover a justiça distributiva e a inclusão social, e das diversas ênfases dadas às suas propostas político-pedagógicas. Refletem assim tendências centrais observáveis no universo de uma centena de CPVCs parceiros da PUC-Rio.

O livro Cursos pré-vestibulares comunitários: espaços de mediaçóes pedagógicas, que reúne as palestras e debates da la Jornada Pedagógica com os CPVCs realizada em outubro de 2004, e os diálogos desenvolvidos desde então com as coordenações pedagógicas dessa centena de núcleos parceiros da PUC-Rio (Carvalho, Alvim Filho, Costa, 2005), oferece elementos para esboçar uma incipiente tipologia, justificável pelo esforço quase didático de 
oferecer cenários em que se desenvolvem diferentes propostas político-pedagógicas. Esses núcleos de CPVCs:

- Procuram definir-se como espaços de formação crítica e de intervenção política, na perspectiva de movimentos de educação popular; assim, o projeto educativo busca compatibilizar os processos de preparação para o vestibular com os de formação política; entretanto, essa práxis pedagógica nem sempre assegura condições suficientes para a construção da formação política nas diversas disciplinas, apesar da centralidade conferida à disciplina Cultura e Cidadania.

- Buscam constituir-se como alternativas de inclusão direcionadas a grupos étnicos e sociais excluídos; lutam por instituir medidas específicas com vistas à inclusão nas agendas das políticas universalistas de medidas específicas em prol da inclusão dos grupos discriminados, como políticas de cotas nas universidades e IES públicas e privadas e de ações afirmativas complementares; sob o prisma mais didático, desenvolvem projetos político-pedagógicos decorrentes dos pressupostos de abordagens crítico-social de conteúdos e do método Paulo Freire; ressaltam processos de ensino-aprendizagem no contexto de um acentuado interacionismo sociocultural entre docentes e discentes, como alternativas de superação das barreiras psicopedagógicas à aprendizagem, de empoderamento coletivo e de convivialidade entre docentes (já há exemplos de ascensão social e educacional) e seus alunos em busca de espaços de afirmação grupal e pessoal.

- Integram-se a uma rede de projetos comunitários mais abrangentes, com várias propostas de inclusão social (níveis escolares, inclusão digital, formação profissional, geração de renda etc.), sob coordenação de uma ONG local ou de associação de moradores, na perspectiva da cidadania ativa e de afirmação da comunidade em sua identidade e diversidade sociocultural; enfatizam-se processos de mediações políticas com o Estado e a sociedade civil visando instaurar localmente recursos de justiça distributiva; os quadros docentes são recrutados na própria comunidade, enfatizam temáticas locais no currículo e operam com recursos físicos, financeiros e humanos mais autóctones, ao mesmo tempo em que buscam respaldos externos mais consistentes. 
- Decorrem de ações institucionalizadas de escolas religiosas e leigas, ou de igrejas e associações filantrópicas, como alternativas do exercício da cidadania e de compromissos pela inclusão social de grupos carentes e/ou de comunidades pobres vizinhas; são patrocinados pela comunidade de pais, professores e alunos, dispondo de relativa autonomia financeira; do ponto de vista pedagógico, a proposta aproxima-se de modelos de educação supletiva de adultos, geralmente implicando um ano de consolidação da educação básica e uma segunda série mais propedêutica.

- Provêm de iniciativas de instituições filantrópicas e de grupos ativos da sociedade civil (igrejas, ONGs e movimentos sociais), operando em seus espaços físicos ou de escolas públicas e privadas em horários cedidos; são dependentes do poder de arregimentação das suas lideranças; contam com quadros docentes de profissionais voluntários, de estagiários e licenciandos de faculdades públicas e privadas; desenvolvem uma proposta pedagógica menos homogênea e mais associada às experiências docentes dos seus colaboradores individuais.

Os cenários de institucionalização dos CPVCs, descritos refletem tendências centrais, mas, por hipótese, podem auxiliar na busca de entendimento sobre a heterogeneidade dos dados estatísticos expressos nos dois surveys.

\section{COMO AFLOROU NA PUC-RIO A “QUESTÃO PEDAGÓGICA” DOS CPVCS?}

A primeira manifestação coletiva e pública da "questão pedagógica" nos CPVCs ocorre em meados de 200I, em uma assembléia de alunos e professores da graduação de Pedagogia. Naquele momento, já havia uma clara consciência de que o tradicional perfil das graduandas de Pedagogia da PUC (normalistas, de classe média, em busca do aumento de seu capital cultural e social) era contrabalançado por $50 \%$ de novas graduandas advindas de CPVCs. O capital social e cultural destas, tão bem analisado por Silva (2003), apresenta, porém, sérias lacunas, especialmente nos processos de compreensão de textos acadêmicos e de expressão estruturada dos discursos escritos (em contraponto ao seu articulado discurso oral). Vera Candau retrata bem essa questão: 
Considero nuclear a necessidade de se trabalhar um novo modelo pedagógico (...) partir de uma visão histórica e construtivista do conhecimento, tanto científico, quanto escolar (...) é necessária uma outra visão do conhecimento. É igualmente importante trabalhar a organização do pensamento (desenvolver habilidades de análise, de síntese, de reflexão), conectada às habilidades da leitura e escrita (um "nó" que muitas vezes explode na universidade) (...) Em minha prática de professora universitária observo que, quando surgem dificuldades no campo da leitura e escrita (...) o grande problema é de organização do pensamento, e não exclusivamente de escrita correta ou incorreta (...) Portanto, o problema é o desenvolvimento de habilidades cognitivas e do pensamento, o que não se faz unicamente por meio de um ensino frontal e expositivo, pois tal desenvolvimento exige outras técnicas pedagógicas que estimulem diferentes habilidades cognitivas. (2005, p.53-54)

O diagnóstico de Candau e sua demanda por um novo modelo pedagógico ainda não encontraram na PUC-Rio uma proposta institucional devidamente articulada. Aquela catarse coletiva dos corpos discente e docente da Pedagogia talvez não tenha tido um impacto similar sobre as demais graduações, e em especial sobre os nove cursos de licenciatura. Por exigência do MEC e do Conselho Nacional de Educação - CNE -, esses cursos deveriam inverter o tradicional esquema de "3 anos de bacharelado + I de formação pedagógica" pela nova proposta definida pelo CNE, no art. $3^{\circ}$ da Resolução 01 , de 18/02/2002: 400 horas de práticas escolares até a metade das licenciaturas; mais 400 horas de estágios docentes na segunda parte das graduações. Essa lógica é particularmente relevante para as licenciaturas da PUC, com um número crescente de alunos oriundos dos CPVCs. Nesse contexto, as coordenações das licenciaturas têm consolidado diversas alternativas de ações tópicas, tais como:

- disciplinas introdutórias voltadas para o desenvolvimento das competências e habilidades na formação do leitor-escritor;

- inclusão digital associada à formação de pesquisador e usuário das ferramentas da web;

- articulações entre o programa comunitário das bolsas sociais e os departamentos para que os alunos tenham oportunidade de realizar cursos mais longos sem o risco de perder as bolsas; 
- adoção de menor número de créditos acadêmicos por semestre letivo, ou mesmo de eventuais repetências em disciplinas;

- inclusão de disciplinas básicas no currículo como pré-requisitos, sem contabilizar créditos acadêmicos;

- atendimento psicopedagógico prestado através do Núcleo de Orientação e Atendimento Psicopedagógico - Noap -, muitas vezes diagnosticando bloqueios de auto-estima, bem mais do que efetivos problemas de aprendizagem;

- medidas socioculturais complementares, na linha de respaldo a eventos étnico-culturais de graduandos afro-descendentes;

- crescente inclusão de graduandos comunitários em grupos de pesquisa, via bolsas de iniciação científica (Pibic, Faperj e outras), estágios remunerados e projetos de extensão universitária.

Ao longo do triênio 2002-2005, era evidente nos órgãos colegiados das licenciaturas, tanto os intracentros quanto os intercentros, a ambivalência entre promover ajustes curriculares, didático-metodológicos, avaliativos, habilitando os docentes a operar melhor com a diversidade e com o multiculturalismo, e adotar práticas compensatórias que permitissem aos graduandos comunitários igualar-se ao perfil antes predominante entre os alunos. A avaliação pessoal do autor é que ainda falta à PUC-Rio uma proposta político-pedagógica institucional articulada, já que as iniciativas "corretivas" mencionadas ocorrem mais por ímpeto de coordenações isoladas nos cursos de graduação, sem um projeto institucionalizado, e inclusive "pré-ativo" nas articulações com os CPVCs e os estabelecimentos de ensino médio públicos e comunitários. De fato, apesar de um discurso recorrente sobre a formação dos licenciandos mediante parcerias (Foerste, 2002), da formação do professor reflexivo em cooperação com a rede municipal de ensino (Cardozo, 2003), da formação dos futuros docentes segundo o método da ação-reflexão-ação com ênfase na resolução de situações-problema (Oliveira, 2004), falta uma agenda mais específica em relação aos CPVCs. A explicação para isso é que se trata de espaços paraescolares, não formais, nos quais se opera em horários incompatíveis com a supervisão dos estágios docentes.

Em 2004, quando a PUC já contava com 140 CPVCs cadastrados, a questão pedagógica ganhou mais relevância em sua política de bolsas sociais: 
de um lado, os CPVCs parceiros buscam alavancar academicamente suas cotas de "bolsas de isenção de taxas escolares" e de "bolsas de permanência" (auxílio-transporte, refeição e material escolar); de outro, os cerca de 600 graduandos demandam crescentemente das licenciaturas e das demais graduações o reconhecimento dos créditos correspondentes a estágios e práticas docentes junto aos seus CPVCs de origem. Como já observamos a propósito da reivindicação de Vera Candau por um novo modelo pedagógico, também as coordenações das nove licenciaturas da PUC carecem de um projeto institucional integrado, capaz de articular o universo acadêmico com os desafios pedagógicos enfrentados no dia-a-dia das salas de aulas dos CPVCs.

Em agosto de 2004, ocorreu o primeiro diálogo ampliado entre os CPVCs associados ao programa de bolsas sociais da PUC e a equipe do Núcleo de Educação de Adultos - Nead Raízes Comunitárias. Naquele momento, a literatura consultada não identificava estudos específicos sobre questões pedagógicas nos CPVCs. Havia a suposição generalizada de que eles adotavam um padrão uniforme em sua organização curricular, nos processos de ensinoaprendizagem e na avaliação, segundo uma lógica muito propedêutica de preparar para os exames vestibulares. Era recorrente a expressão "gabaritar provas seletivas", que significa utilizar provas aplicadas em anos anteriores pelas universidades mais prestigiosas. Se para o senso comum havia uma suposta sintonia fina ou atrelamento dos CPVCs ao modelo de preparar alunos para a aprovação nas provas seletivas, diversos "ruídos" pareciam indicar dissonâncias em relação a essa práxis. Vários CPVCs, especialmente os associados a conceituados colégios católicos, como o Santo Inácio (Projeto Invest) e o Teresiano (Projeto Êxito), reestruturam, então, seus projetos pedagógicos em cursos prévestibulares de dois anos, com a opção pedagógica de a primeira série buscar articular a formação desejável de ensino médio.

\section{DIMENSÕES PEDAGÓGICAS DOS CPVCS: SURVEY COM ALUNOS}

A aplicação de uma prova, baseada nos padrões de conteúdos e forma dos Enem de 2002 e 2003, criou a oportunidade de se desenvolver um exame simulado junto aos 97 CPVCs parceiros do $1{ }^{\circ}$ Ciclo de Diálogos Pedagógicos sobre o Enem, junto a docentes desses cursinhos. Apesar de ter sido realizada em um sábado de junho de 2005, dia útil para muitos trabalhadores- 
estudantes, 2.783 pré-vestibulandos comunitários experimentaram esse teste simulado. Um mês depois da prova simulada, na $5^{a}$ Jornada de Formação sobre o Enem, coordenadores e docentes dos 97 CPVCs tiveram o retorno sobre o rendimento agregado de cada cursinho, em cada uma das 42 questões da prova, comparado à média nacional do Enem e à média geral dos 97 cursos co-irmãos. A equipe de avaliação da Fundação Cesgranrio comentou a lógica da estruturação interna de cada item, as habilidades e competências associadas à matriz do Enem e os padrões de acertos e erros dos CPVCs. Junto com a prova simulada, foi aplicado o questionário de um survey, visando identificar as características socioeconômicas e escolares dos estudantes, assim como suas percepções acerca dos processos pedagógicos adotados em seus cursinhos, com referência a quatro blocos temáticos: organização curricular, processos de avaliação, coordenação pedagógica e características didáticometodológicas.

O bloco temático sobre as percepções dos alunos quanto aos conteúdos programáticos curriculares desenvolvidos por seus CPVCs mostra que há uma forte ênfase - no cômputo de $80 \%$ dos alunos, e acima da nota sete (na escala de dez) - de que prevalece a tônica propedêutica para o processo seletivo de acesso ao ensino superior; desses $80 \%$, um subgrupo de $25,6 \%$ confere a nota máxima (dez) na escala de focalização sobre as provas vestibulares. A pesquisa revela também que a ênfase programática na formação em Política e Cidadania é ainda maior, pois $83,9 \%$ dos alunos Ihe conferem o patamar mínimo (sete), e aproxima-se de um terço $(30,4 \%)$ a proporção dos que conferem a nota máxima (dez), nessa ótica de formação sociopolítica crítica. Em contrapartida, a ênfase curricular centrada na formação básica, correspondente ao ensino médio, apresenta uma distribuição de graus mais equilibrada, com 30,2\% dos alunos conferindo grau seis, 32\% entre sete e oito e $29 \%$ entre nove e dez pontos. A percepção de que a organização curricular nos cursinhos comunitários depende dos professores, individualmente, e da natureza das diversas disciplinas mostra-se estatisticamente mais dispersa: 52\% dos alunos atribuem uma nota menor que sete e cerca de $25 \%$, entre nove e dez.

○loco temático sobre os procedimentos de avaliação desenvolvidos nos 97 CPVCs compreendia quatro dimensões: avaliar sob a tradicional ênfase em exames vestibulares; desenvolver um processo avaliativo mais próximo da matriz do Enem, ressaltando-se a interdisciplinaridade e a contextualização 
dos temas; dar maior destaque à avaliação sobre os conteúdos programáticos do ensino médio; reconhecer uma sistemática de avaliação flexível, decorrência de uma equipe docente complexa e majoritariamente integrada por voluntários. Empiricamente, observa-se um padrão homogêneo nas percepções dos alunos sobre as ênfases: em avaliação propedêutica para os exames vestibulares, 57,9\% dos alunos dão nota de oito a dez, e 54,5\% atribuem o mesmo peso à perspectiva de uma avaliação voltada para o domínio de conteúdos programáticos do ensino médio. Processos de avaliação mais interdisciplinares e contextualizados, na perspectiva do Enem, são reconhecidos com notas baixas (até cinco) por 15\% dos alunos, e entre seis e sete por 23,1\%, embora mais de um terço (34\%) confira pesos entre oito e nove. Uma sistemática de avaliação mais dependente dos professores individuais e/ou da natureza das disciplinas é reconhecida com os percentuais mais baixos de incidência por metade dos estudantes.

Os itens do survey relativos às características predominantes no exercício da coordenação pedagógica nos CPVCs retratam padrões bastante uniformes na distribuição dos pesos atribuídos pelos pré-vestibulandos: o predomínio das funções mais burocráticas é reconhecido por 58,9\% dos pesquisados, com os níveis mais elevados da escala (oito a dez), enquanto as funções técnicas de acompanhamento dos processos de ensino-aprendizagem e de articulações curriculares são reconhecidas por 56,4\%. Entretanto, as dimensões de inter-relações nas instâncias comunitárias e de práticas voltadas à orientação vocacional e profissional alcançam menos de um terço (31,9\%) de graus inferiores a cinco.

O quarto bloco temático do survey incluía questões de cunho didáticometodológico e epistemológico sobre os processos de ensino-aprendizagem desenvolvidos nos CPVCs. Na única pesquisa de nosso conhecimento sobre tais dimensões, desenvolvida entre 2000 e 2003 (http://www.gecec.pro.br), Vera Candau e a equipe do Grupo de Estudos sobre Cotidiano, Educação e Cultura(s) - Gecec - diagnosticaram cinco padrões associados à Educação Multicultural, tal como concebida por J. A. Banks: desenvolvimento de uma prática pedagógica tradicional baseada em uma visão bancária do processo cognitivo; desarticulação entre o conhecimento escolar e os conhecimentos socioculturais de referência desses grupos de alunos comunitários; formas de ensino expositivo, frontal; ausência de um ensino cooperativo mediante a construção de comuni- 
dades de aprendizagem entre professores e alunos; segmentação da integração dos conteúdos de ensino, e mesmo do empoderamento discente, no desenvolvimento dos processos de análise, síntese e reflexão. $\bigcirc$ survey buscou operacionalizar em itens do questionário essas dimensões apontadas pelo estudo de campo do Gecec, e retratou empiricamente as seguintes características nos processos de ensino-aprendizagem recorrentes nos CPVCs:

I. A não-associação entre os conteúdos das matérias ensinadas e as experiências de vida e os conhecimentos de alunos mais adultos e mais trabalhadores é a única variável retratada com predominante ênfase negativa pela maioria dos 2.783 pré-vestibulandos; atribui-se a recorrência sempre em I 3\% dos casos; e freqüentemente em 37\% das respostas. Em contrapartida, as taxas de presença de integração alcançam 46,3\% de aprovação dos alunos, embora pouco mais de um décimo dos estudantes ( 1 I,8\%) afirme que raramente tal integração ocorre na prática.

2. Quando essa variável é controlada pelas condições de trabalho dos pré-vestibulandos comunitários, observa-se a mesma média de $50 \%$ de respostas críticas, comparativamente a alunos não trabalhadores. Mas é entre os pré-vestibulandos há mais tempo afastados da rede escolar (que concluíram o ensino médio há seis anos ou mais) que se alcança a taxa mais negativa: $81 \%$.

3. A apresentação dos conteúdos programáticos das disciplinas como produtos prontos e em pacotes, sem a devida reconstrução pelos alunos é assinalada como incidente por $28,4 \%$ dos pré-vestibulandos. Contudo, mais de dois terços $(67,6 \%)$ não percebem tal lacuna, em especial um subgrupo de $27,5 \%$, para os quais ela nunca ocorre. Diversas variáveis de controle (condições de trabalho, carreiras almejadas no ensino superior, prazo maior na conclusão do ensino médio etc.) não chegam a alterar os padrões de percepção desses segmentos socioeducacionais.

4. $O$ reconhecimento de que é preciso variar os estilos na forma de ensinar nos CPVCs é manifesto por 42,9\% dos pré-vestibulandos comunitários, entre os quais uma proporção majoritária (26,3\%) expressa que tal característica ocorre freqüentemente. Em oposição, 
no universo geral dos pesquisados, 53, I \% não percebem esse traço formalista e tradicional de ensino nas classes dos CPVCs. Entretanto, os pré-vestibulandos trabalhadores, os que concluíram o ensino médio há mais tempo e aqueles com carreiras universitárias mais indefinidas apresentam, em média, seis pontos percentuais a menos em seus padrões de respostas.

5. A falta de um ensino mais cooperativo, sem que alunos e professores constituam uma comunidade de aprendizagem, não é admitida nos CPVCs por mais de dois terços (68,8\%) dos alunos. A discrepância acentuada entre as observações de campo pela equipe do Gecec e as percepções dos pré-vestibulandos comunitários sugere a formulação de uma hipótese ad hoc. o espírito de cooperação predominante nos CPVCs e o elevado senso de compromisso de professores e alunos criam uma perspectiva de interacionismo simbólico tão dinâmica sobre os processos de ensino-aprendizagem, tão cooperativa e comunitária do ponto de vista do inter-relacionamento humano, que talvez não permita a devida percepção, pelo prisma propriamente epistemológico, das dificuldades referentes a um construtivismo sociointeracionista, como pressuposto pelo Gecec.

6. A última dimensão pesquisada reporta-se a uma questão nuclear, em termos das propostas político-pedagógicas dos CPVCs, especialmente nos núcleos associados à rede Educação e Cidadania de Afro-descendentes e Carentes - Educafro - e ao movimento Pré-Vestibular para Negros e Carentes - PVNC: os modos de trabalhar as questões de preconceito social, racismo, solidariedade, empoderamento. A hipótese de que tais conteúdos e ênfases ocorram nas disciplinas das áreas de humanas e sociais, mas estejam ausentes nas disciplinas de ciências, é rejeitada por 58,3\% dos pesquisados, dos quais cerca de $25 \%$ declaram que isto nunca se verifica. Já entre o contingente de $38,2 \%$ de alunos com percepções críticas sobre essa integração didática e curricular, apenas 14,7\% reconhecem que sempre se observa esse fosso. Tal padrão de percepções não se altera, mesmo quando se recorre a certas variáveis de controle, como condição de trabalhador-estudante, pré-vestibulandos aspirantes às áreas técnicocientíficas e biomédicas na universidade. 


\section{DIMENSÕES PEDAGÓGICAS DOS CPVCS: SURVEY COM DOCENTES}

O survey foi realizado junto ao universo de 270 docentes e coordenadores por ocasião da I Jornada Pedagógica com os CPVCs parceiros da PUCRio, em outubro de 2004, com uma taxa de respostas de $52 \%$ dos participantes. Uma análise mais detalhada do survey e de seu questionário e o texto integral do livro que se reporta a esses dados estão disponíveis na biblioteca central da PUC-Rio (Carvalho, Alvim Filho, Costa, 2005).

\section{Características dos processos ensino-aprendizagem}

As características estruturantes dos CPVCs - espaços de exercício de cidadania ativa, ambientes escolares não formais, mas que objetivam o êxito no ingresso em universidade e locais comunitários de reforço à escolaridade secundária - condicionam opções pedagógicas bastante diversificadas em relação a metodologias de ensino-aprendizagem e propostas curriculares. A par disto, seus quadros docentes são constituídos majoritariamente por graduandos, muitas vezes sem uma preparação pedagógica mais sistematizada nas licenciaturas, e cujas experiências podem tender a opções mimetizadas por suas vivências pessoais de sucesso ou estar referenciadas em seus mestres mais bemsucedidos.

Talvez pela natureza social dos CPVCs, observa-se entre seus professores e dirigentes uma forte tendência a se reportar ao educador Paulo Freire, a correntes pedagógicas sociocríticas sobre os conteúdos escolares e a propostas pedagógicas associadas ao multiculturalismo e à diversidade. Em contraponto às abordagens pedagógicas críticas está o realismo dos conteúdos curriculares exigidos e escrutinizados nas provas de seleção das universidades mais competitivas. A representante da população afro-descendente no Conselho Nacional de Educação, professora Petronilha B. Gonçalves e Silva, reflete sobre essas ambivalências inerentes aos CPVCs:

...a competitividade, acirrada pelo crescente número de concluintes do ensino médio (...) tornou quase obrigatória a passagem por um cursinho, com a finalidade de receberem informações e também apoio afetivo, no sentido de garantir autoconfiança para enfrentar a arena dos exames vestibulares. Provas estas em 
que devem mostrar competências necessárias para ultrapassar o vestíbulo (daí os vestibulares) dos estabelecimentos de ensino superior e, assim, ingressar em um novo universo de estudos e conhecimentos. (2002, p. II)

Este estudo propôs-se a identificar a diversidade de correntes pedagógicas sobre os processos de ensino-aprendizagem e, em especial, a mapear as múltiplas correntes didático-metodológicas predominantes nos espaços dos CPVCs. Dada a inexistência de literatura específica sobre o tema e a conveniência de subsidiar uma base de informações a docentes e coordenadores de CPVCs, foi oferecida, no próprio corpo do questionário do survey, uma sistematização das principais escolas e correntes pedagógicas, com base na obra de Mizukami ( |99|). O autor valeu-se da articulada síntese de Mizukami para delinear dimensões analíticas, construtos e variáveis sobre ensino-aprendizagem.

Ressalte-se a relativa heterogeneidade de formação acadêmica existente na equipe docente de cada CPVC, geralmente constituída por 12 a 15 docentes. Ela atende, de um lado, à grade curricular tradicional do ensino médio e, de outro, às especificidades das áreas dos exames pré-vestibulares. São docentes voluntários, majoritariamente graduandos ainda em processo de formação em cursos de licenciatura e bacharelado, com diferentes faixas etárias e tempo diverso de ingresso nos CPVCs, os quais comungam um compromisso social e comunitário.

A tabela I retrata essa ampla heterogeneidade, não só na composição das equipes docentes, como também na diversidade de abordagens e ênfases teórico-práticas sobre ensino-aprendizagem. De maneira geral, duas abordagens metodológicas - o ensino contextualizado na comunidade e na cidadania e o ensino com ênfase em relações de desenvolvimento interpessoal - são reconhecidas como relevantes por $66 \%$ dos entrevistados. Reforça-se assim a ênfase comum entre dirigentes e docentes dos CPVCs na identidade sociocultural, no empoderamento e na cidadania.

Sua contrapartida manifesta-se na negação, pela maioria, da existência de um processo de ensino-aprendizagem baseado na competitividade: apenas 29, 1 \% reconhecem sua relevância. Já a concepção didática mais conservadora - o ensino calcado na figura do docente - está presente nos cursinhos na opinião de metade dos pesquisados. Quando o retrato estatístico é considerado sob a perspectiva dos diversos grupos integrantes da amostra de profes- 
sores, as características predominantes são: os mais jovens tendem a reproduzir as tendências gerais observadas; os que ainda cursam a graduação têm uma visão bastante diversificada sobre a prevalência dos diversos métodos de ensino; os formados em Ciências Sociais, emblematicamente, atribuem relevância zero a métodos de ensino voltados à competitividade no âmbito dos seus grupos sociais; entre aqueles com maior tempo de militância nos CPVCs, 75\% têm uma postura favorável e sólida em relação à abordagem de ensino contextualizado sobre a realidade social e comunitária.

TABELA I

PERCEPÇÕES DOS DOCENTES SOBRE DIFERENTES ABORDAGENS DE ENSINO-APRENDIZAGEM

\begin{tabular}{l|c|c|c|c|c}
\hline $\begin{array}{l}\text { Enfases metodológicas percebidas } \\
\text { nos CPVCs }\end{array}$ & Total* & $\begin{array}{c}\text { Docentes de } \\
\text { I6 a I8 anos }\end{array}$ & $\begin{array}{c}\text { Docentes com } \\
\text { curso superior } \\
\text { incompleto }\end{array}$ & $\begin{array}{c}\text { Docentes } \\
\text { formados em } \\
\text { Ciências Sociais }\end{array}$ & $\begin{array}{c}\text { Docentes } \\
\text { veteranos } \\
\text { ePVCs }\end{array}$ \\
\hline No docente & $50,0 \%$ & $56,5 \%$ & $54,0 \%$ & $38,5 \%$ & $50,0 \%$ \\
No ensino construtivista e ativo & $56,3 \%$ & $47,8 \%$ & $64,1 \%$ & $41,7 \%$ & $25,0 \%$ \\
No desenvolvimento interpessoal & $65,9 \%$ & $73,9 \%$ & $64,5 \%$ & $61,5 \%$ & $0 \%$ \\
Na competitividade e no êxito & $29,1 \%$ & $39,1 \%$ & $34,9 \%$ & $0 \%$ & $0 \%$ \\
no exame & & & & & \\
No ensino contextualizado e & $65,4 \%$ & $60,9 \%$ & $70,3 \%$ & $53,8 \%$ & $75,0 \%$ \\
na cidadania
\end{tabular}

* | 40 aproximadamente igual a $52 \%$ de 270 docentes e coordenadores. Fonte: Carvalho, Alvim Filho, Costa, 2005, p.34.

\section{Características dos procedimentos curriculares}

Há três décadas a Sociologia do Currículo provoca profundas divisões teórico-práticas no Brasil. Especificamente em relação ao ensino médio - com reflexo direto sobre os CPVCs -, a questão curricular polariza-se com os $\mathrm{Pa}$ râmetros Curriculares Nacionais do MEC, de 1997, e com a Resolução n.3 do CNE sobre as Diretrizes Curriculares Nacionais, de 1998. De um lado, com base nos Parâmetros Curriculares Nacionais para o Ensino Médio - PCNEM e nas Diretrizes Curriculares Nacionais para o Ensino Médio - DCNEM -, enfatizam-se: o ensino médio vinculado ao trabalho e à prática social; compe- 
tências cognitivas para conhecimento dos fundamentos científicos e tecnológicos, mais do que conteúdos curriculares; língua e demais linguagens, como recursos para construir significados (Mello, 2004). De outro, especialmente nas Faculdades de Educação e nas licenciaturas, predomina uma abordagem sociocrítica do currículo escolar que ressalta: a submissão dos PCNEM à lógica do mercado; o discurso híbrido das DCNEM sobre competências cognitivas; a técnica gerencial de controle, implicada na articulação de habilidades e competências; a necessidade de se redefinirem as competências a partir da realidade dos alunos e de sua escola (ver nova proposta de PCNEM, apresentada pelo MEC em novembro de 2004

Tendo em conta a especificidade dos CPVCs, o questionário do survey explorou duas dimensões: I. Que ênfases no currículo são percebidas pelos pesquisados? 2. Qual a abordagem curricular preferida? Em relação às abordagens percebidas, foram considerados quatro fatores, vistos como os mais recorrentes na seleção de conteúdos curriculares: gabaritos de exames vestibulares anteriores; conteúdos importantes do ensino médio em si; conteúdos curriculares emanados da própria proposta político-pedagógica do CPVC; seleção curricular feita individualmente pelos próprios docentes.

Uma hipótese ad hoc sugere a ocorrência de múltiplos fatores condicionantes, tais como: heterogeneidade das equipes docentes dos cursinhos comunitários; supervisão pedagógica bastante fluida, potencializando ênfases mais individualizadas de acordo com os campos científicos das disciplinas; experiências e estratégias de aprendizagem vivenciadas pessoalmente pelos docentes; carência de projetos de formação das equipes docentes, prévia e em serviço; barreiras objetivas para maior integração dos docentes em reuniões pedagógicas.

Esses fatores podem explicar como quatro abordagens curriculares, em princípio contrastantes entre si, são percebidas como concomitantes para a grande maioria dos entrevistados. Elevadas taxas percentuais oscilam entre a ênfase curricular associada à proposta pedagógica dos cursinhos (76\%) e a percepção dos currículos a partir dos próprios docentes (86\%). Talvez o dado mais surpreendente seja o fato de os gabaritos de exames supletivos anteriores não pesarem sobre a seleção curricular, o que, em princípio, seria bastante provável pela prática recorrente aos exames simulados.

Delineia-se assim um cenário bastante heterogêneo quanto às percepções sobre as ênfases concorrentes ora predominantes nos CPVCs, e quanto 
às abordagens curriculares desejáveis. Esse retrato estatístico parece refletir as características referentes às abordagens curriculares: uma heterogeneidade explicável, talvez, pela carência de maior articulação pedagógica interna nos CPVCs, gerada por lacunas nos processos de formação da equipe docente em seu acompanhamento técnico-pedagógico.

\section{Processos de formação docente}

Mesmo sucinto, um diagnóstico estatístico revela condições desafiadoras para uma adequada política de preparação dos quadros de professores nos CPVCs parceiros da PUC-Rio. Na rede de ensino regular supõe-se que os quadros docentes já qualificados previamente em cursos de licenciatura devem desenvolver projetos de formação continuada em serviço a fim de assegurar um trabalho coletivo articulado em torno de um projeto pedagógico comum. Nos CPVCs esses requisitos têm outras particularidades. Seus docentes apresentam a potencialidade do compromisso cívico por uma causa coletiva comunitária, mas, em contrapartida, são geralmente leigos, com reduzida disponibilidade de tempo, sem recursos técnicos e material didático adequados e sem uma infra-estrutura em termos de recursos físicos. Neste contexto mais restrito, a formação docente - prévia ou continuada - é um potencial espaço de mediações técnico-pedagógicas à disposição dos CPVCs.

Entretanto, segundo o survey aplicado aos participantes das jornadas na PUC-Rio, apenas um quinto dos CPVCs desenvolvia um processo articulado de formação de seus quadros docentes. Assim, 80,3\% deles não eram percebidos como atuantes na qualificação prévia ou continuada de suas equipes docentes. Esse dado reforça a necessidade de um investimento mais consistente no âmbito dessas mediações pedagógicas, não apenas por parte de cada cursinho comunitário, como também de suas parcerias interinstitucionais com universidades e licenciaturas. Apesar do reduzido contingente de $20 \%$ de CPVCs com processos formativos dos docentes, menos da metade (9\%) é percebida como atuante no desenvolvimento de uma formação adequada a seu projeto político-pedagógico. Este dado tão limitado aponta para o uso indevido do principal recurso técnico-pedagógico acessível aos CPVCs para a formação dos seus quadros docentes, inegavelmente o mais valioso recurso disponibilizado voluntariamente por seus colaboradores. 
Essa lacuna, percebida na institucionalização da formação das equipes docentes pelos CPVCs, pode estar associada a uma controvérsia pedagógica que desde 1983 é recorrente entre educadores brasileiros. A tese de doutorado de Guiomar Namo de Mello destaca, por exemplo, a relevância da competência profissional ou técnica do magistério paulistano, a par de seu compromisso político em favor de condições adequadas de escolaridade para as camadas populares. Paulo Nosella, por sua vez, critica os pressupostos das competências técnico-pedagógicas no processo de ensino-aprendizagem dos saberes escolares, ressaltando, em contrapartida, a relevância de conteúdos sociocríticos na escola popular. Dermeval Saviani (1983) busca ainda uma síntese dessas posições. Ao longo das duas últimas décadas, essa controvérsia prossegue, e mais recentemente ganhou novos contornos, como a dicotomização entre "educação de qualidade cognitivista" (como a atribuída aos PCNEM e à matriz de avaliação do Enem) e "qualidade social da educação", com destaque em projetos político-pedagógicos em prol de uma cidadania ativa, consciência crítica, convivialidade, valorização da diversidade cultural.

No survey foi formulada uma questão aberta em relação à controvérsia entre competência técnica e compromisso político, solicitando-se que os docentes a associassem ao contexto dos seus CPVCs. Os dados empíricos indicam que: quase um quinto dos pesquisados (19,3\%) reconhece a relevância da controvérsia, apresentando justificativas para suas respostas; mais de um terço $(36,8 \%)$ reconhece a relevância da questão, sem contudo expressar bem o seu significado pedagógico; pouco mais de um quinto $(21,1 \%)$ ressalta a existência de compromisso político; proporções menores atribuem a ocorrência da controvérsia à debilidade técnica; e outros 7\% não atribuem relevância à questão.

\section{Características da coordenação pedagógica}

Dada a premissa de que a coordenação pedagógica é um recurso e um espaço das mediações pedagógicas disponíveis para os CPVCs, o retrato estatístico que emerge do survey revela características desafiadoras. Por exemplo: a coordenação pedagógica é reconhecida como atuante em 58\% dos cursinhos, inexistindo, portanto, em $42 \%$ dos casos. Dentro do grupo majoritário, destacam-se três dimensões do exercício da coordenação: em menos de um quinto 
( 19\%), o acompanhamento feito pela coordenação pedagógica envolve retorno e repasse de informações e de apoio técnico a seus quadros docentes; em 44,5\%, ocorre um acompanhamento pela coordenação pedagógica sem, entretanto, haver repasse de dados ou oferta de apoio aos docentes; em 36,5\%, a coordenação pedagógica não envolve acompanhamento às práticas docentes.

No intento de entender os recursos e processos pedagógicos nos CPVCs como espaços de mediações para assegurar maior eficácia, eficiência e efetividade às ações desses movimentos sociais e comunitários, parece que se configura um amplo potencial, não devidamente explorado, no âmbito das funções da coordenação pedagógica nos CPVCs. Um indicador complementar dos processos de gestão e capacidade gerencial mostra a freqüência de reuniões pedagógicas em um movimento social que envolve especialmente membros voluntários e, no caso dos que funcionam aos sábados e domingos, um imenso espírito de interesse coletivo. Os dados do survey indicam que são realizadas de quatro a cinco reuniões por ano em 36,9\% dos CPVCs; até três reuniões em percentual semelhante dos casos, seis ou mais reuniões anuais em $27,1 \%$, o equivalente a uma reunião bimestral em cerca de um quarto dos cursinhos.

survey forneceu ainda dados relativos à duração média da formação prévia dos docentes: em $61 \%$ dos casos, essa formação dura apenas duas horas, e em apenas $10 \%$ alcança o máximo de oito horas, ou seja, uma jornada integral de formação prévia.

Já em resposta a uma questão aberta do questionário "Como tornar a coordenação pedagógica dos CPVCs mais eficaz?”, é possível condensar as alternativas propostas em três tendências: desenvolver novos procedimentos técnico-pedagógicos (46,8\%); consolidar procedimentos técnico-administrativos (23,4\%); oficializar uma unidade de coordenação pedagógica $(29,8 \%)$.

\section{O PROUNI E OS DILEMAS GERADOS À PARCERIA PUC-RIO/CPVCS}

Em recente audiência pública na Assembléia Legislativa do Estado do Rio de Janeiro em torno da Carta do Rio, no item referente à política de cotas nas universidades federais, a PUC-Rio relatou sua experiência na institucionalização de uma cota de bolsas sociais em prol dos CPVCs. O processo foi descrito sob três eixos de ações, ao longo do período 1994-2006. 
I. A tríplice missão estatutária da PUC como universidade religiosa, porém ecumênica; como universidade comunitária, em especial por sua diaconia evangélica junto às comunidades mais pobres, fator determinante da sigla do Nead Raízes Comunitárias, e, no caso específico do Grande Rio, da origem do PVNC, hoje oficialmente instituído como Rede Educafro, junto às comunidades eclesiais de jovens na Baixada Fluminense; e como universidade filantrópica, agora sob a égide do Prouni e da política federal de renúncia fiscal, gerando I0\% de bolsas integrais e parciais em cada um dos cursos de graduação. Essas bolsas, agregadas a outras modalidades, totalizam 4.295, o que representava 37,5\% de bolsistas entre os 11.447 alunos da graduação no início de 2006.

2. A crescente articulação de uma política de bolsas sociais junto aos CPVCs parceiros (620 atualmente), com iniciativas no plano acadêmico, como adoção de disciplinas introdutórias para o desenvolvimento de competências e habilidades na formação do leitor-escritor; inclusão digital articulada à formação do usuário dos recursos na web; recursos técnico-administrativos para evitar jubilações nas hipóteses de alongamento dos cursos do ciclo básico e de repetências; adoção de disciplinas de crédito zero para matérias de pré-requisito acadêmico; e atendimento psicopedagógico prestado através do Noap. E, ainda, com a implementação de uma política de complementação financeira, cobrindo auxílio-transporte, alimentação, reprodução de material escolar e, em escala reduzida, oferecendo ajuda-moradia por meio do Fundo Emergencial de Solidariedade da PUC (www.pucrio.br/pastoral), que atendia 645 alunos carentes em 2005 e projeta chegar a mil em 2006.

3. Como universidade filantrópica, a PUC-Rio vive no biênio 2005-2006 os impactos gerados pelo Prouni, ao redefinir os critérios para fixação de bolsas integrais e parciais em cada um dos cursos de graduação, na proporção de um décimo da receita gerada pelos alunos pagantes. Em 2005, todos os cursos de graduação da PUC incluíam alunos bolsistas do Prouni. Já os dados de matrícula em 2006 indicam a alocação de 4.295 bolsas (correspondentes a 37,5\% da matrícula total). Esses dados destacam o impacto gerado pelo Prouni sobre o 
processo de parcerias com os CPVCs e apontam declínio da cota de reserva a partir de 2006.

Esse cenário criado pelo Prouni já sinaliza claramente diversos impactos diretos e indiretos sobre os processos pedagógicos vivenciados pelos CPVCs, em especial nos 97 cursos comunitários participantes dos ciclos de formação pedagógica da PUC-Rio. Ao associar o processo seletivo das 220 mil bolsas previstas para 2005-2006 aos resultados do Enem, o MEC provoca dois efeitos paradoxais: simultaneamente ao aumento quantitativo das oportunidades de bolsas totais e parciais para os seus alunos, os CPVCs defrontam-se com o aumento qualitativo das médias exigidas nos resultados no Enem, especialmente nas habilidades e competências da prova de redação. Quase como corolário desta nova política de bolsas do Prouni em universidades do perfil da PUC-Rio, os CPVCs passam a concorrer, desde 2005, com um novo contingente de alunos pobres no ensino médio, em particular aqueles oriundos de escolas públicas de excelência, como os Centros de Apoio Psicossocial - CAPs -, Centros Federais de Educação Tecnológica - Cefets -, escolas militares etc., que competem com os pré-vestibulandos comunitários em condição desvantajosa para estes, uma vez que os primeiros contam com um maior capital escolar e cultural.

É crucial ressaltar, neste momento, uma hipótese de trabalho que tem norteado as ações compensatórias de natureza pedagógica co-patrocinadas em 2005-2006 pelo Nead Raízes Comunitárias junto aos 97 CPVCs parceiros:

I. A preocupação dos CPVCs deve deslocar-se de uma proposta pedagógica sobre a sua capacitação propedêutica para promover o acesso à universidade por meio de exames vestibulares, para uma proposta pedagógica que promova uma qualitativa escolaridade de educação básica, que a Constituição Federal de 1988 assegura a todos os brasileiros, como direito público subjetivo, portanto inalienável.

2. Ao institucionalizar, via Enem, o processo seletivo para as 220 mil bolsas do Prouni, o MEC aumenta as exigências quanto a conhecimentos, competências e habilidades segundo a matriz cognitivista daquele exame, capaz de conferir a uma política quantitativa de aumento de vagas para o ensino superior requisitos qualitativos educa- 
cionais. Mesmo os seus críticos ligados à proposta pedagógica da "qualidade social em educação" reconhecem esse efeito como tendo sido promovido pelos sistemas de avaliação do Sistema Nacional de Avaliação da Educação Básica - Saeb - e do Enem. Sob tal premissa, consideramos muito positiva para a filosofia político-ideológico-pedagógica dos CPVCs a revisão da tradicional ênfase propedêutica em seus cursinhos comunitários e a preocupação com a qualidade da educação, sem prejuízo de seu compromisso político nuclear com as causas da cidadania ativa, da diversidade e multiculturalismo e do empoderamento comunitário. Esta alternativa técnico-pedagógica e técnico-política é sintetizada por Dermeval Saviani em sua tréplica a Guiomar N. Mello e Paolo Nosella :

Cabe unificar as lutas, visando consolidar os avanços e tornar irreversíveis as conquistas feitas, trilhando um caminho sem retorno no processo de reapropriação, por parte das camadas trabalhadoras, do conhecimento elaborado e acumulado historicamente. (apud Carvalho, Alvim Filho, Costa, 2005, p.239)

\section{PROPONDO O DEUS JANOS COMO PATRONO PEDAGÓGICO}

Segundo a mitologia romana, a divindade Janos protegia o acesso aos vestíbulos dos palácios dos nobres (ou seriam os pré-vestibulares do mundo acadêmico?), mantendo uma face direcionada aos pórticos da entrada e a outra aos caminhos que permitiam aos viajantes ter acesso aos palácios romanos. Pedagogicamente, é também indispensável que os CPVCs e seus parceiros acadêmicos, como a PUC-Rio e tantas outras universidades e IES brasileiras, se repensem como Janos: é importante ter o olhar centrado nos vestíbulos da entrada ao mundo acadêmico, para assegurar o acesso à universidade de qualidade a crescentes contingentes de alunos, lutando junto às suas comunidades nos CPVCs, mas é igualmente crucial e imprescindível manter uma face voltada para o caminho difícil e sucateado de grande parte das escolas de ensino médio e da educação básica nas escolas brasileiras. É um requisito da democracia e das políticas de ação afirmativa não apenas assegurar condições efetivas de acesso à universidade, mas também garantir as condições objetivas 
de uma escolaridade básica de qualidade como lastro educacional, científico e cultural para uma melhor formação universitária; para a mobilidade social, ocupacional e econômica; para o crescente empoderamento político de suas comunidades e para que essas comunidades possam desenvolver projetos alternativos de autodesenvolvimento e de inclusão coletiva. Mesmo reconhecendo-se a pertinência dos vivos debates entre competência técnica e compromisso político no âmbito dos CPVCs, é crucial retomar-se a síntese proposta por Dermeval Saviani:

A identificação dos fins implica imediatamente a competência política, e mediatamente a competência técnica; a elaboração dos métodos para atingi-los implica a competência técnica, e mediatamente a competência política (...) Logo, sem competência técnico-política não é possível sair da fase romântica (...) triIhar um caminho sem retorno no processo de reapropriação, por parte das camadas trabalhadoras, do conhecimento elaborado e acumulado historicamente. (Saviani, 1983, p. I42)

A luta político-educacional da sociedade civil por alternativas de ação afirmativa e de inclusão, expressa significativamente pelo movimento social dos CPVCs em suas diversas instâncias (Educafro, PVNC, Movimento dos sem Universidade - MSU -, grupos eclesiais de base, associações de moradores etc.), obtém da sociedade política - seja através do Prouni, que criou 220 mil novas vagas em IES privadas, seja pelo crescente avanço das políticas de cotas nas universidades públicas - uma instigante valorização pedagógica, ao instituir o processo seletivo de acesso às universidades com base no Enem. Esta tendência de tomar o Enem como referência para ingresso no ensino superior representa quase uma revolução paradigmática em relação aos CPVCs, na superação de seu anterior viés de recorrer a práticas pedagógicas de "gabaritar" os processos de ensino-aprendizagem, seleção curricular e avaliação, a partir de provas seletivas dos exames vestibulares. O Enem representa, portanto, a alternativa para repensar suas propostas pedagógicas, segundo a matriz de competências e habilidades a serem construídas ao longo de uma educação básica de qualidade.

Reforça-se assim a simbologia ao deus Janos como patrono dos CPVCs: ampliar as oportunidades de acesso aos vestíbulos das universidades mediante 
um processo de formação qualitativa na educação básica, a partir de procedimentos técnico-pedagógicos mais consistentes nas esferas de currículo, didática, avaliação e formação de seus quadros docentes. De fato, estima-se que, na média, o êxito dos CPVCs no acesso à universidade é de $20 \%$. Constatase ainda que $20 \%$ dos atuais pré-vestibulandos ainda são alunos do ensino médio regular, buscando nos CPVCs oportunidades de aprendizagem ausentes na sua escola regular. Portanto, cerca de $60 \%$ dos atuais pré-vestibulandos comunitários poderão obter uma educação básica mais consistente, dentro de uma proposta pedagógica menos propedêutica e mais articulada à matriz do Enem, que Ihes abra oportunidades de ascensão social e ocupacional em outras modalidades de ensino superior, tecnológico e pós-médio bem maiores do que o restrito grupo dos atuais $20 \%$ com acesso à universidade.

\section{REFERÊNCIAS BIBLIOGRÁFICAS}

BOUDON, R. Efeitos perversos e ordem social. Rio: Zahar, 1987.

CANDAU, V. M. F. Os desafios pedagógicos na formação docente dos CPVCs. In: CARVALHO, J. C.; ALVIM FILHO, H.; COSTA, R. P. (orgs.) Cursos pré-vestibulares comunitários. espaços de mediações pedagógicas. Rio de Janeiro: Editora da PUC-Rio, 2005. p.46-55.

CARDOZO, S. A Universidade e a escola: uma via de mão dupla? Rio de Janeiro, 2003. Dissert. (mestr.) PUC-RJ.

CARVALHO, J. C.; ALVIM FILHO, H.; COSTA, R. P. (orgs.) Cursos pré-vestibulares comunitários. espaços de mediações pedagógicas. Rio de Janeiro: Editora da PUC-Rio, 2005.

FOERSTE, E. Parceria na formação de professores. do conceito à prática. Rio de Janeiro, 2002. Dissert. (mestr.) PUC-RJ.

FUNDAÇÃO CESGRANRIO. Relatório técnico sobre os resultados da prova. Rio de Janeiro, jul. 2005. (mimeo)

HABERMAS, J. Consciência moral e agir comunicativo. Rio de Janeiro: Tempo Brasileiro, 1989.

HIRSCHMAN, A. Auto-subversão: teorias consagradas em xeque. São Paulo: Companhia das Letras, 1997.

KERLINGER, F. N. Foundations of behavioral research: educational and psychological inquiry. New York: Holt, Hinehart, 1984. 
MELLO, G. N. Educação escolar brasileira: o que trouxemos do século XX. Porto Alegre: Artmed, 2004

MIZUKAMI, M. G. Métodos e técnicas de ensino-aprendizagem. São Paulo: EPU, 1991.

OLIVEIRA, F. S. Uma universidade de pesquisa frente à formação de professores. Rio de Janeiro, 2004. Dissert. (mestr.) PUC-Rio.

SAVIANI, D. Competência política e compromisso técnico, ou o pomo da discórdia e o fruto proibido. Educação e Sociedade, n. I 5, p. I I - | 43, ago. 1983.

SILVA, J. S. Por que uns e não outros? Caminhada de jovens pobres para a universidade. Rio de Janeiro: 7 Letras, 2003.

SILVA, P. B. G. e. Prefácio. In: ANDRADE, R. M. T.; FONSECA, E. F. (orgs.) Aprovados. cursinho pré-vestibular e população negra. São Paulo: Selo Negro, 2002. p. I I - 12

Recebido em: março 2006

Aprovado para publicação em: abril 2006 